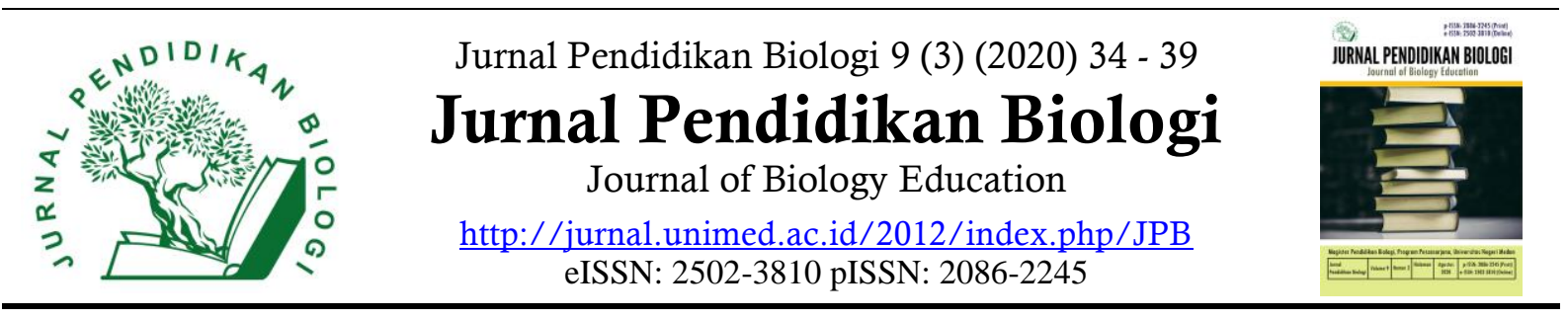

\title{
Hubungan Keterampilan Proses Sains dengan Praktikum ditinjau dari Hasil Belajar Peserta didik SMA Negeri 19 Makassar
}

\author{
Satriani, Nursaida Hardiyanti \\ Program Studi Pendidikan Biologi, STKIP Yapti Jeneponto, Jl. M. Ali Dg. Gassing No. 1, Jeneponto, 92315, \\ Sulaweai Selatan, Indonesia
}

\section{INFO ARTIKEL}

\section{Histori Artikel}

Received 27 Nopember 2020

Revised 10 Desember 2020

Accepted 15 Desember 2020

Published 30 Desember 2020

\section{Keywords:}

Science Process Skills,

Practicum Implementation,

Learning Outcomes

\begin{abstract}
Biology learning has an important role in developing students' competencies by emphasizing direct learning or real experiences through practicum implementation. The purpose of this study was to determine the relationship between science process skills and practicum in terms of learning outcomes of class XI MIPA students at SMA Negeri 19 Makassar. The type of research used is ex post facto correlational research. The research sample consisted of 64 students who were selected by purposive sampling. The instrument used was a questionnaire for practicum implementation and science process skills, documentation by collecting all student learning outcomes for the 2019/2020 academic year. Data analysis used Pearson Product Moment correlation test and path analysis. The data obtained were analyzed descriptively and inferential analysis using the SPSS version 20 computer application. The sig value was obtained. $0.000<0.05$ and the value of $\mathrm{R}$ Square shows the number 0.535 , which means that the implementation of practicum has a $53.5 \%$ relationship effect with science process skills when viewed from the learning outcomes of students.
\end{abstract}

Copyright (C) 2021 Universitas Negeri Medan. Artikel Open Access dibawah lisensi CC-BY-4.0 (https://creativecommons.org/licenses/by/4.0)

How to Cite

Tedrita, M. (2020). Analisis Kesalahan Mahasiswa pada Penyelesaian Soal Mata Kuliah Anatomi \& Fisiologi Manusia. Jurnal Pendidikan Biologi, 9(3), x-xx.

\section{PENDAHULUAN}

Ilmu Biologi merupakan ilmu yang berkaitan dengan bagaimana cara peserta didik mencari tahu tentang lingkungannya secara sistematis. Biologi menjadi salah satu ilmu yang berkembang dari serangkaian metode ilmiah. Pembelajaran biologi berorientasi terhadap penguasaan pengetahuan, konsep sains, dan penguasaan sikap sains yang harus dikembangkan oleh peserta didik (Astuti et al,
2019). Pelaksanaan praktikum menjadi salah satu syarat dalam pembelajaran biologi yang bertujuan agar sikap psikomotirk peserta didik dapat ditingkatkan. Selain itu, Praktikum dapat memberi kesempatan peserta didik untuk belajar melalui pengalaman nyata sehingga memudahkan peserta didik dalam memahami teori biologi (Lauren et al., 2016).

Dalam proses pembelajaran, kegiatan praktikum dilaksanakan untuk mencapai tujuan tertentu. Pada pembelajaran biologi 
tujuan yang ingin dicapai adalah kegiatan yang berkaitan dengan belajar konsep ilmiah, proses pengembangan keterampilan, dan meningkatkan pemahaman teori pembelajaran. Kegiatan praktikum berkaitan dengan pengembangan keterampilan-keterampilan dalam pembelajaran biologi, sehingga siswa mampu merefleksikan pengalaman sendiri dan mencoba menggunakan apa yang telah dipelajari sebelumnya (Hamidah et al., 2014).

Efektifitas proses pembelajaran dengan melaksanakan kegiatan praktikum, akan memfasilitasi peserta didik untuk lebih mengerti konsep dan prinsip sains dan mampu menggunakan pengetahuan tersebut dalam kehidupan sehari-hari (Yuanita 2018). Analisis keterampilan proses sains dalam proses pembelajaran berbasis praktikum dapat membentuk karakteristik peserta didik dalam berinovasi mengembangkan keterampilan proses pembelajaran (Lepiyanto 2014). Praktikum dilaksanakan dengan tujuan untuk memberi pengalaman kepada peserta didik baik itu diranah afektif, kognitif dan psikomotorik. Pada ranah afektif, siswa dilatih untuk bersikap ilmiah selama kegiatan praktikum. Pada ranah kognitif, peserta didik mendapatkan kesempatan untuk lebih memahami konsep materi dan memperoleh pengetahuan baru dari penemuan dari hasil praktikum. Sedangkan pada ranah psikomotorik, peserta didik data melatih dan mengembangkan keterampilan baik itu dalam menggunakan alat dan bahan ataupun dalam menerapkan teori dan konsep ilmu biologi (Lathiifa et al., 2019).

Melalui kegiatan pengamatan, pembelajaran sains akan menghasilkan berbagai kesimpulan sesuai dengan informasi yang diperoleh. Keinginan manusia untuk mengetahui bagaimana prinsip kerja dari ilmu sains mengenai alam akan terorganisir dalam kegiatan penyelidikan menjadi suatu kumpulan pengetahuan yang menjelaskan keteraturan di alam dan penyebab keteraturan itu dapat terjadi (Yudiarsahi 2011).

Laboratorium beserta peralatan yang ada di dalamnya merupakan sarana dan prasaran penting untuk menunjang proses pembelajaran. Kegiatan yang dilaksanakan di dalam laboratorium memiliki peran penting dalam pembelajaran sains karena memberi banyak manfaat bagi peserta didik terutama dalam pengembangan keterampilan (Lestari \& Nirva D. 2018). Laboratorium dibutuhkan sebagai salah satu prasarana pembelajaran yang digunakan sebagai tempat untuk melatih peserta didik dalam memahami teori dan meningkatkan keterampilan melalui metode ilmiah dalam proses pelaksaanan praktikum (Emda 2014).

Keterampilan proses sains menekankan adanya penumbuhan dan pengembangan sejumlah keterampilan tertentu dalam diri siswa sehingga mereka mampu memproses informasi untuk memperoleh berbagai fakta, konsep maupun pengembangan konsep dan nilai (Tawol \& Liliasari 2014). Memperkuat daya imajinasi siswa yang terlibat dalam kegiatan praktikum memfasilitasi mereka untuk mengembangkan kreativitas dalam menerapkan materi-materi biologi yang telah disampaikan oleh guru mereka selama proses pembelajaran yang diaplikasikan selama tahap praktikum yang dilaksanakan (Salam et al., 2010).

Hakikatnya pembelajaran biologi berkaitan dengan adanya proses pelaksanaan praktikum dengan mementingkan keterampilan proses sains yang dapat menunjang pencapaian hasil belajar siswa. Sehingga perlu dilakukan penelitian tentang hubungan keterampilan proses sains dengan praktikum ditinjau dari hasil belajar peserta didik kelas XI MIPA SMA Negeri 19 Makassar. 


\section{METODE}

Jenis penelitian ini adalah penelitian ex post facto bersifat korelasional, yaitu untuk menguji hubungan antar variable bebas dengan variable terikat serta untuk menguji hipotesis yang dirumuskan. Penelitian ini terdapat tiga variabel yaitu variabel independent (bebas) yakni keterampilan proses sains (X1) dan pelaksanaan praktikum (X2) dan variabel dependent (tak bebas) hasil belajar biologi (Y1). Teknik pengambilan sampel dilakukan secara purposive sampling dan terpilih sebanyak 64 peserta didik. Tekhnik pengumpulan data dilakukan dengan menyebarkan angket mengenai angket keterampilan proses sains yang diisi oleh guru bidang study Biologi dan pelaksanaan praktikum yang diisi oleh peserta didik serta dokumentasi hasil belajar Biologi tahun ajaran 2019/2020. Teknik analisis data dalam penelitian ini adalah analisis deskriptif dan statistic inferensial menggunakan uji korelasi Product Moment Pearson dan analisis jalur (path) yang dihitung dengan menggunakan SPSS versi 20.0 untuk menguji ada tidaknya hubungan antara keterlaksanaan praktikum dengan hasil belajar melalui keterampilan proses sains.

\section{HASIL DAN PEMBAHASAN}

\section{Paparan Data Keterampilan Proses Sains Peserta Didik}

Proses pengumpulan data variabel keterampilan proses sains dilakukan dengan cara guru bidang studi biologi mengisi angket keterampilan proses sains dengan berdasar pada nilai keterampilan (Psikomotorik) peserta didik tahun ajaran 2019/2020. Hasil perhitungan angket keterampilan proses sains dapat digambarkan pada Tabel 1 berikut.

Tabel 1. Persentase Skor Keterampilan Proses Sains

\begin{tabular}{cccc}
\hline Rentang Nilai & Jumlah & Persentase & Kategori \\
\hline $80-100$ & 24 & 37,50 & Sangat Baik \\
$66-79$ & 23 & 35,74 & Baik \\
$56-65$ & 10 & 15,63 & Cukup \\
$46-55$ & 7 & 10,93 & Kurang \\
$0-45$ & 0 & 0 & Sangat Kurang \\
\hline Jumlah & $\mathbf{6 4}$ & $\mathbf{1 0 0}$ & \\
\hline
\end{tabular}

Hasil analisis data menunjukkan tingkat keberagaman persentase penguasaan keterampilan proses sains peserta didik kelas XI SMA Negeri 19 Makassar. Kategori sangat baik berada pada angka 37,50, kategori baik berada pada angka 35,74 , kategori cukup berada pada angka 15,63 dan kategori rendah berada pada angka 10,93. Hal ini menandakan bahwa keterampilan proses sains peserta didik sebagian besar sudah berada pada tingkat penguasaan yang baik. Pengembangan keterampil-an proses sains dapat dilatih dengan bereksperimen melalui kegiatan praktikum, dimana siswa mendapatkan peluang untuk berekplorasi menumbuh-kan kemampuan berfikir, bekerja dan bersikap ilmiah sebagai aspek penting dalam pengaplikasianya di kehidupan sehari-hari (Emda 2014). Keterampilan proses sains melalui metode ilmiah mengakomodasi peserta didik untuk melakukan kegiatan pengamatan, merumuskan masalah, berhipotesis, melakukan percobaan dan menarik kesimpulan (Handayani, et al. 2016).

Penelitian yang dilakukan oleh (Salosso et al., 2018) menyimpulkan bahwa KPS yang tergolong sangat baik adalah keterampilan mengelompokkan, menerapkan konsep, 
menggunakan alat/bahan, mengamati, keterampilan merencanakan percobaan, berkomunikasi, meramalkan, dan menafsirkan, sedangkan keterampilan yang tergolong kurang adalah keterampilan mengajukan pertanyaan.

Pada dasarnya aspek keterampilan proses sains sudah ada dalam diri setiap peserta didik, hanya saja keterampilan tersebut perlu dilatih agar dapat diaplikasikan selama proses pembelajaran dan kehidupan sehari-hari. Oleh karen itu, untuk mengembangkan keterampilan sains peserta didik diperlukan prmbelajaran yang berbasis praktikum. Sejalan dengan penelitian yang dilakukan oleh (Lathiifa et al.,
2019), bahwa melalui kegiatan praktikum dapat memberi pengalaman kepada peserta didik baik itu diranah afektif, kognitif dan psikomotorik. Hal tersebut dibuktikan dari hasil penelitiannya diperoleh skor 0,874 yang berarti terdapat hubungan positif dan signifikan terhadap pelaksanaan praktikum dan keterampilan generic sains dengan hasil belajar peserta didik.

\section{Paparan Data Pelaksanaan Praktikum}

Hasil analisis perhitungan angket keterlaksanaan praktikum yang telah dilakukan dapat digambarkan pada Tabel 2 berikut.

Tabel 2. Persentase Keterlaksanaan Praktikum

\begin{tabular}{cccc}
\hline Rentang Nilai & Jumlah & Persentase (\%) & Kategori \\
\hline $80-100$ & 49 & 76,57 & Sangat tinggi \\
$60-79$ & 15 & 23,43 & Tinggi \\
$40-59$ & 0 & 0 & Cukup \\
$20-39$ & 0 & 0 & Rendah \\
$0-19$ & 0 & 0 & Sangat Rendah \\
\hline Jumlah & $\mathbf{6 4}$ & $\mathbf{1 0 0}$ & \\
\hline
\end{tabular}

Berdasarkan hasil analisis data diperoleh persentase tingkat keterlaksanaan praktikum peserta didik berada pada dua tingkat kategori yaitu, kategori sangat tinggi dengan nilai 76,57, dan kategori tinggi dengan nilai 23,43 . Hal tersebut menandakan bahwa tingkat keterlaksanaan praktikum terlaksana dengan baik. Salah satu manfaat praktikum adalah memberi wadah bagi peserta didik untuk merefleksikan materi pembelajaran, sehingga peserta didik dapat membuktikan dan menemukan teori terhadap materi pembelajaran yang akan merasionalisasi (Rustaman \& Nuryani 2005).

Sesuai dengan hasil penelitian (Lepiyanto 2014) menjelaskan bahwa dengan menerapkan metode praktikum dapat melatih peserta didik untuk menganalisis dan menarik kesimpulan secara mandiri sehingga dapat meningkatkan keterampilan proses sains dan keterampilan kognitif siswa dalam proses pembelajaran. Keterampilan akademik melalui kegiatan praktikum menjadi salah satu factor dalam meningkatkan hasil belajar karena peserta didik akan dengan sendirinya melatih diri untuk berfikir kritis dalam mengidentifikan dan menyelesaikan permasalahan dialami. Sebagai akibat dari proses tersebut maka kemampuan kognitif peserta didik secara efektif dapat terpakai (Cahyanigrum et al., 2013).

\section{Paparan data hasil belajar Biologi Peserta didik}

Data hasil belajar biologi peserta didik dapat digambarkan pada Tabel 3 berikut. 
Tabel 3. Persentase Hasil Belajar Biologi

\begin{tabular}{cccc}
\hline Interval Skor & Jumlah & Persentase (\%) & Kategori \\
\hline $85-100$ & 32 & 50 & Sangat Tinggi \\
$65-84$ & 32 & 50 & Tinggi \\
$55-64$ & 0 & 0 & Cukup \\
$35-54$ & 0 & 0 & Kurang \\
$0-34$ & 0 & 0 & Sangat Kurang \\
\hline Jumlah & $\mathbf{6 4}$ & $\mathbf{1 0 0}$ & \\
\hline
\end{tabular}

Tabel 4. Dekomposisi Kontribusi Setiap Variabel Penelitian

\begin{tabular}{cccc}
\hline Pengaruh Variable & Nilai Koefisien Jalur & Nilai Koefisien Determinasi (R2) & Sig. \\
\hline $\mathrm{X}_{1}$ dengan $\mathrm{X}_{2}$ & 0,446 & 0,398 & 0,000 \\
$\mathrm{X}_{1}$ dengan $\mathrm{X}_{2}$ ditinjau dari $\mathrm{Y}$ & 0,630 & 0,535 & 0,000 \\
\hline
\end{tabular}

Hubungan Keterampilan Proses Sains dengan Praktikum ditinjau dari Hasil Belajar Biologi Melalui Peserta Didik

Hasil analisis data yang diperoleh dari proses analisis jalur (path analysis) dapat digambarkan melalui Tabel 4. Hasil analisis data menunjukkan bahwa nilai koefisien jalur antara variabel $\mathrm{X}_{1}$ dengan variable $\mathrm{X}_{2}$ adalah sebesar 0,446 dan pengaruh variabel $\mathrm{X}_{1}$ dengan variable $\mathrm{X}_{2}$ ditinjau dari variable $\mathrm{Y}$ memiliki nilai koefisien jalur sebesar 0,630 , sesuai dengan pedoman interpretasi korelasi menandakan bahwa adanya hubungan yang cukup kuat antara keterampilan proses sains dengan praktikum jika ditinjau dari hasil belajar. Selain itu, diperoleh nilai probabilitas Sig. $0,05 \geq 0,000$, dan nilai $R$ square menunjukkan angka 0,535 yang artinya pelaksanaan praktikum memiliki pengaruh hubungan sebesar 53,5\% dengan keterampilan proses sains ditinjau dari hasil belajar peserta didik.

Kegiatan praktikum berperan penting dalam proses pembelajaran biologi karena menjadi salah satu wadah bagi peserta didik untuk mengembangkan dan meningkatkan aspek-aspek keterampilan sains. Selain itu, praktikum juga memberi kesempatan bagi siswa untuk menumbuhkan sikap psikomotrik melalui pengalaman nyata (Lauren et al., 2016).
Dalam kegiatan laboratorium siswa diberi kesempatan untuk memenuhi keingintahuannya dalam menerapkan konsep materi dan menemukan pengetahuan baru (Emda 2014).

Kegiatan praktikum menjadi salah satu syarat dalam mengembangkan keterampilan dasar eksperimen yang meliputi tahapan mengamati, mengestimasi dan memanipulasi peralatan biologi. Berkaitan dengan hal tersebut, kegiatan praktikum menunjang terlaksananya pendekatan ilmiah, sehingga dapat memberikan pengalaman bagi siswa dalam mengembangkan aspek-aspek keterampilan selama mengikuti setiap tahap proses praktikum (Rustaman Y \& Nuryani 2005).

\section{KESIMPULAN}

Berdasarkan hasil analisis serta pembahasan hasil penelitian, maka diperoleh kesimpulan bahwa terdapat hubungan yang positif dan sinifikan antara keterampilan proses sains dengan praktikum yang ditinjau dari hasil belajar peserta didik dengan nilai koefisien korelasi 0,535 yang artinya keterampilan proses sains memiliki pengaruh hubungan sebesar 53,5\% dengan praktikum ditinjau dari hasil belajar. Kegiatan praktikum membiasakan peserta didik untuk mengikuti proses dan 
melakukan pengamatan yang dapat mengembangan keterampilan proses sains sehingga jika ditinjau dari hasil belajar peserta didik akan lebih mampu mengerti terkait konsep dan prinsip-prinsip materi biologi.

\section{DAFTAR PUSTAKA}

Astuti, Nuning Widya, Yolida Berti, \& Sukumbang Darlen. (2019). Hubungan Praktikum dan Keterampilan Proses Sains terhadap Hasil Belajar Materi Ekosistem. Jurnal Bioterdidik, 7(5).

Bahruddin \& Esa, E. N. (2007). Teori Belajar dan Pembelajaran. Malang: Ar-Ruzz Media.

Cahyanigrum, S. N., Eddy S., \& Solichin. (2013). Hubungan Antara Life Skills dengan Hasil Belajar Praktikum Pengelasan di SMKN 1 Trenggalek. Jurnal Teknik Mesin, 21(2).

Emda, A. (2014). Laboratorium sebagai Sarana Pembelajaran Kimia dalam Meningkatkan Pengetahuan dan Ketrampilan Kerja Ilmiah. Lantanida Journal, 2(2).

Hamidah, A. Eka, N. S., Retni S., \& Budianingsih. (2014). Persepsi Siswa Tentang Kegiatan Praktikum Biologi di Laboratorium SMA Negeri Se-Kota Jambi. Jurnal Sainsmatika FKIP Universitas Jambi, 8(1).

Handayani, Sin Syin Lu'Lu, Suciati, \& Marjono. (2016). Peningkatan Keterampilan Proses Sains pada Pembelajaran Biologi Melalui Penerapan Model Bounded Inquiry Lab. Jurnal Bioedukasi, 9(2), 1693-265X.

Lathiifa, N. N., Berti Y., \& Marpaung, R. R. T. (2019). Hubungan Pelaksanaan Praktikum dan Keterampilan Generik Sains dengan Hasil Belajar Peserta Didik Kelas VII. Jurnal Bioterdidik. 7(5).

Lauren I., Fauziyah H, Tumiur G. (2016). Uji Kelayakan Penuntun Praktikum Genetik
Berbasis Keterampilan Proses Sains Berdasarkan Ahli Materi dan Ahli Desain. Jurnal Pendidikan Biologi, Vol. 6, No. 1, 2016.

Lestari, M. Y., \& Nirva, D. (2018). Keterampilan Proses Sains (KPS) Pada Pelaksanaan Praktikum Fisika Dasar I. Indonesian Journal of Science and Mathematics Education, 01(1), 49-54.

Lepiyanto, A. (2014). Analisis Keterampilan Proses Sains pada pembelajaran berbasis praktikum. Bioedukasi Jurnal Pendidikan Biologi Universitas Mmhammadiyah Metro, 5(2).

Rustaman Y, Nuryani. (2005). Strategi Belajar Mengajar Biologi. Malang: UN Press.

Salam, Haipan. Agus Setiawan, Ida Hamidah. (2010). Pembelajaran Berbasis Virtual Laboratory untuk Meningkatkan Penguasaan Konsep pada Materi Listrik Dinamis. Porcedding of The $4^{\text {th }}$ Internasional Comprence on Teacher Education; Join Conference UPI \& UPSI Bandung, Indonesia, 8-10 November 2010.

Salosso, Serly Wahyuni, Nurlaili, \& Ratna Kusumawardani. (2018). Analisis Keterampilan Proses Sains Siswa SMA Melalui Penerapan Model Pembelajaran Learning Cycle 5E pada Pokok Bahasan Larutan Asam dan Basa. Bivalen: Chemical Studies Journal 1(1).

Suryani, S., Ely, R., \& Tyas A. P. (2014). Pengaruh Experiential Learning Kolb Melalui Kegiatan Praktikum Terhadap Hasil Belajar Biologi Siswa. Journal of Biologi Education, 3(2).

Tawol \& Liliasari. (2014). Keterampilan-Keterampilan Sains dan Implementasinya dalam Pembelajaran $I P A$. Makassar: UNM Press.

Yuanita. (2018). Analisis Keterampilan Proses Sains Melalui praktikum IPA Materi bagian-bagian bunga dan biji pada mahasiswa PGSD STKIP Muhammadiyah Bangka Belitung. Jurnal Pemikiran dan Pengembangan SD, 06(1), 27-35.

Yudiarsahi, E. (2011). Sains dan Metode Ilmiah. Depok: Universitas Indonesia. 